paper on "Slavic Intellectual Societies in Nineteenth Century Austria" at the Bi-State (Kansas and Missouri) Slavic Conference at the University of Missouri at Kansas City on October 16, 1965.

\title{
ADDITIONS TO LIBRARY COLLECTIONS
}

The Colorado State University library has recently acquired about $\mathbf{5 0 0}$ items on Hungarian literature and history. Most of them deal with the nineteenth and twentieth centuries.

The library of Southern Illinois University at Edwardsville has recently procured more than 500 volumes on all phases of Hungarian culture, life, and history. Most of the works are in English. Among them is a good collection on Louis Kossuth.

The Lypynsky East European Institute (1204 West Lindley Ave., Philadelphia, $\mathrm{Pa}$. 19141) possesses a valuable collection of material dealing with the history of Galicia under Habsburg rule and Austro-Ukrainian relations in 1918. Detailed information about the collection may be obtained from Mr. Eugene Zyblykevych, the director of the Institute.

Papers relating to the Georgia Salzburgers are in the De Renne collection at the University of Georgia and in the library of the Salzburger Society at Savannah.

The University of Michigan library has recently acquired a set of the stenographic protocols of the proceedings of the Hungarian parliament which is almost complete for the period between 1861 and 1935. In addition, it has purchased a complete set of the stenographic protocols for the 1st-22nd sessions (1861-1917) of the Austrian Haus der Abgeordneten and of the 1st-12th sessions (1861-1918) of the Herrenhaus. Except for the fact that the protocols for the 47 th and 48 th sessions are missing, the library has also acquired a complete set of the stenographic protocols of the 1st-49th sessions (1861-1918) of the Delegation des Reichsrates.

Among other volumes, the Rice University library has recently acquired the following items which might be of interest to the readers of the Yearbook: Die Presse, December, 1899-1918 and July, 1920-January 20, 1939 (microfilm); Arbeiter Zeitung, January, 1932-February 12, 1934, and 
August 5, 1945, to December, 1948 (microfilm) ; Archiv für österreichische Geschichte, Vols. I-CXXIV (1848-1965); österreichisches Historisches Jahrbuch, Vols. I-III (186365) ; Österreichisches Jahrbuch, Vols. I-V (1877-81), VII-IX (1883-85), XII-XIII (1888-89), XV-XXI (1891-97), XXIIIXXXI (1899-1907), XXXIII-XXXIV (1909-10), and for the years 1925-36, 1947-49, 1951-56, 1958, 1960, and 1961; österreichische Zeitschrift für Volkskunde, Vols. I-XII (1895-1906) and XIV-XXIII (1908-17); Wochenschrift für Volkswirtschaft und Statistik, Vols. VIII-XIX (1856-67); Neue Ordnung. Blätter für Christliche Gesellschaftserneuerung im Sinne des Linzer Programmes, Vols. I-VI (1925-31); Jahrbuch für Landeskunde von Niederösterreich, Vols. I-XXI (1902-28), XXIII-XXIX (1940-48), and XXXI (1953-54); Unser Heimat. Monatsblatt des Vereins für Landeskunde von Niederösterreich und Wien, 1928-38; Verein für Geschichte der Stadt Wien, Abhandlungen (193?-40), Mitteilungen, Vols. I-XVII (1919/20-38), and Jahrbuch, Vols. I (1939) and III-XVI (1942-60); Zeitschrift für Oberösterreichische Geschichte, Landes- und Volkskunde, 1919-28; Carniola. Zeitschrift für Heimatkunde, 1908-18; Steiermärkische Zeitschrift, 1821-34; Századok, 1954-65; and Acta Historica (Budapest), 1951-65.

Research Materials in the Field of Austrian History acquired

by the University of North Carolina Library in 1964-65

Acta Sacrae Congregationis De Propaganda Fide Res Gestas Bohemicas Illustrantia (1622-1624) (5 vols., Prague, 1923-55).

Archiv für die Landesgeschichto des Herzogthums Krain, 1852-54. 3 vols.

Athenaeum: Listy pro literaturu a kritiku védeckou, edited by T. G. Masaryk (9 vols., Prague, 1884-92).

Austria, Reichsgesetzblatt, 1849-1918. 71 vols.

Bibliografia Romana-Ungara (1473-1878) (3 vols., Bucharest, 1931-35).

Bohemia: Jahrbuch des Collegium Carolinum, 1960-.

Bratislava: Casopis Učené společnosti Safařikovy, 1927-37. 11 vols. 
Bundesgesetzblatt für die Republik Österreich, 1918-60. 74 vols.

Carniola: Zeitschrift für Heimatkunde, 1908-18. 9 vols. Ceská akademie vèd a umèní, Almanach, 1891-1940. 51 vols. Čská akademie vèd a umění, V̌estník, 1892-1952. 60 vols.

Cirkevné listy (46 vols., Turčianský Svätý Martin, 18871943).

Fontes Rerum Bohemicarum (7 vols., Prague, 1873-1907).

Gesellschaft für Geschichte der Juden in der Tschechoslowakischen Republik, Jahrbuch, 1929-38. 9 vols.

Jahrbuch für österreichische Landwirte (Prague), 186181.20 vols.

Magyar Történeti Bibliografia, 1825-1867 (3 vols., Budapest, 1950).

Mitteilungen des österreichischen Staatsarchivs, 1948-61. 14 vols.

Moravslié zemské desky (1480-1642) (4 vols., Brno, 194853).

Naše řĕc, 1917-61. 44 vols.

Naše Slovensko: Mèsíčnik pro hájeni zájemü uherských Slovakti, 1907-9. 3 vols.

Obzor národohospodářský, 1896-1940. 45 vols.

Österreichische Osthefte, 1959-.

Österreichisches Jahrbuch, 1877-1910. 34 vols.

österreichische Vierteljahrsschrift für Rechts- und Staatswissenschaft, 1858-66. 18 vols.

Orol tatránski, 1845-48. 3 vols.

Prameny $k$ dèjinám tricetileté války (1618-1648) (6 vols., Prague, 1951-57).

Sbornik archivnich praci, 1951-63. 12 vols.

Sborník vèd právních a státnich, 1901-39. 23 vols. 
Scriptores Rerum Bohemicarum (3 vols., Prague, 17831829).

Scriptores Rerum Hungaricarum (2 vols., Budapest, 193738).

Silesia Antiqua, 1959-.

Slovenskje narodñje novini, 1845-48. 4 vols.

Slovenskje pohladi na vedi, umenja a literaturu, 1846-52. 4 vols.

Stenographische Berichte des Böhmischen Landtages, 18631908. 50 vols.

Stenographische Berichte über die Verhandlungen des Schlesischen Landtages, 1861-1914. 45 vols.

Stifter Jahrbuch, 1949-.

Tätigkeit der sozialdemokratischen Abgeordneten im österreichischen Reichsrat (later Nationalrat), Heft 1-21 (Vienna, 1907-27).

Ungarische Jahrbücher (Berlin), 1922-36. 15 vols.

Verein für Geschichte der Deutschen in Böhmen, Jahrbuch, 1926-33. 3 vols.

Verein für Geschichte der Stadt Wien, Jahrbuch, 1939-60. 16 vols.

Veroin für Geschichte der Stadt Wien, Mitteilungen, 191938. 17 vols.

Wiener Archiv für Geschichte des Slawentums und Osteuropas, 1955-.

University of North Carolina

JOSEF ANDERLE

\section{SPECIAL ANNOUNCEMENTS}

The Inter-University Committee on Travel Grants will again have fellowships available for advanced graduate students and faculty members to study in Czechoslovakia and Hungary in 1967-68. Periods of study ranging from one semester to one calendar year can be arranged. The deadline 